\title{
Interview
}

\section{Interview with Dejan Mladenovic of Hallmark Cards}

\section{Andy Knaggs}

is Editor, PrintMedia Management.

Keywords: pre-press, MediaBase, Hallmark Cards, DAM, Digilink, indexing

Abstract With MediaBase, Hallmark found a system that was affordable, provided good value for money and was designed by people with prepress experience. Equally important was the process that Hallmark undertook. In daily usage, the asset management system is proving invaluable.

Journal of Digital Asset Management (2007) 3, 164-166. doi:10.1057/palgrave.dam.3650080

If at first you don't succeed, try, try again, goes the old proverb, often attributed to Robert the Bruce in history who, while supposedly in hiding from the English in 1306, watched a spider continually trying to spin a web despite frequent failure. Legend has it that he was inspired by this to return to the fray, eventually gaining Scottish independence after the battle of Bannockburn.

The proverb is a lesson though that persistence can pay off, and this seems to have been the key for Hallmark Card's attempts at developing a digital asset management system that delivered the efficiencies it was looking for.

"It took about six years and three attempts to get a system successfully working," says Dejan Mladenovic, Hallmark's prepress manager at its European production site in The Netherlands. "Our biggest goal with this was to make sure our Mac designers can spend more time being creative instead of searching for files."

Hallmark has somewhere around 95,000 greeting card design records uploaded on to the system it has now settled on - one based on the MediaBase product from Digilink. The system is called Gallery at Hallmark, and its success is underlined by the fact that at the same time last year there were only 78,000 design records online.

The vagaries of greeting card production require Hallmark to be working almost two years ahead of itself - artwork that is being created today is due to hit the market in 2009 - and that brings with it certain design and production issues that Mladenovic works to help the product groups to resolve. Cards are printed in the Far East and in Eastern Europe, and that adds further logistical issues to the mix.

"People think that making a card is a very simple thing, and it is in some respects, but making sure it's printed on the right paper, that it gets distributed and is in shops at the right time for the customer takes a lot of planning," says Mladenovic. "Where I come in is trying to find the best possible way of getting the file to the printers."

Previously Hallmark used to send CDs by messenger, which was obviously expensive. The biggest issue from an IT perspective was security. Hallmark's production teams migrated to Mac OSX and Adobe CS2 in September last year, which improved the security of its systems. This will allow online access to artwork files for printers and other suppliers.

Back in 1999, Hallmark had a CD cabinet holding around 2,000 CDs. Despite an indexing system, it was still troublesome to search for and retrieve assets. It became increasingly clear that Hallmark needed something better. It looked firstly at a number of ready-made solutions from major digital asset management vendors.

"These products did not speak to our databases though, and the makers were not from the prepress industry, so they didn't 
know how we think," explains Mladenovic. Hallmark's US operation in Kansas was already using a huge DAM, which was quite old already at this point. After a lot of research and testing, Hallmark went for a DVD jukebox system. It was to be "the worst decision we ever made," says Mladenovic. There were hardware problems and as these gathered pace there was a negative impact on production.

With MediaBase, Hallmark found a system that was affordable, had a good value for money, was designed by people with prepress backgrounds so they understood Hallmark's requirements, and could be linked to Hallmark's database systems, such as its JD Edwards accounting package.

"Digilink were very quick in customising the solution for us; getting it to interface with all our databases. They were very flexible, and easy to work with, and the training was very easy," says Mladenovic.

This was a solution that worked, and not just because of the nature of the product and the vendor, says Mladenovic. Equally important was the process that Hallmark undertook. There were no rushed, and therefore no rash, decisions. A project team encompassing staff from several different areas of the company was formed to finally cure Hallmark's asset management ills, and although Gallery was first installed three years ago, the first year and a half was spent talking and listening.

He continues: "When we did this implementation we did everything by the book, according to project management rules. We talked to people for about one and a half years, we asked questions about what they wanted from the system. Our colleagues from Hallmark International came to help on a project level. We visited a lot of companies using the same product, trying to find any possible flaw in it. Then we came home and talked to our users here.

"It's now a great success story because more and more departments will be using it. It has possibilities for creating a specific interface for each user, so they will only see what you want them to."

Mladenovic says it was a very conscious decision to form a team composed of disparate people because he did not want "a bunch of people saying 'yes you are right'."
"By choosing the work project from different people you have someone that might be against everything we say. It creates a healthy atmosphere, and it makes us check everything before we go to the steering committee. If they agree, it has to be good, it's been checked by everybody."

Gallery is now fully operational, and is accepting Adobe InDesign and PDF documents onto the system. Hallmark is looking at opening it up to sister companies around the world, and to printers in the Far East. "It will mean that if there any mistakes in the file rendering, we can react," Mladenovic points out.

And the system will grow with Hallmark's needs. That was in fact one of the major attractions of MediaBase, says Mladenovic. It has become a management tool, because records have to be created in the JD Edwards system before they can go to Gallery, and if they are not in Gallery, then production cannot start.

Gallery is capable of pulling out metadata from the file itself, whether it is a Photoshop, InDesign or Quark file. It also imports a lot of metadata from JD Edwards, and it has some editable fields where users can input information. A multi-lingual capability is also important for the system, as Hallmark has production around the world.

In daily usage, the asset management system is proving invaluable. Mladenovic says: "What we wanted, and what we've got, was to know where every design was used and in which card. I can tell you exactly where a design originates, where it was used in the US and here in Europe, and how many times it has been used. There are cross-referencing possibilities within Gallery."

"On the next level we have records of how well the card is selling, and putting those two things together, that's when DAM becomes a marketing tool. The index will show whether a design is a seller or a non-seller. That's a development I'm expecting."

At this point in the long and sometimes torturous road that Hallmark has traveled in search of digital asset management happiness, Mladenovic can reflect with some satisfaction on a job well done. He says the value of a very long research period, talking to the users, and understanding 
where the DAM will be implemented and the processes and the cultural differences between departments and countries it must bridge, have been big lessons.

"If people are not enthusiastic about it, that's it, it won't work. You should not try to push it to people. You shouldn't tell them they must use it, but you tell them it's there. We had two attempts that did not work out well. The first was a one man show. The second was left to prepress. Then we involved everybody and it works. In our team we had the Doubting
Thomas's and the cheerful ones, but everyone had to be happy and that's why it was a success,' he reasons.

While it is difficult to quantify exactly what the savings will be for the card manufacturer, he considers that it has certainly provided more creative time, and made production processes much faster and more efficient. Production has increased by 30 per cent, he says, yet no additional staff members have had to be employed. These are production efficiencies that any creator of printed work would greet enthusiastically. 